Check for updates

Cite this: RSC Adv., 2019, 9, 16718

\title{
A nonlinear optical switch induced by an external electric field: inorganic alkaline-earth alkalide $\uparrow$
}

\begin{abstract}
Bo Li, (D) a Daoling Peng, ${ }^{\text {a }}$ Feng Long Gu (D) *a and Chaoyuan Zhu (D) ab
Exploring a new type of nonlinear optical switch molecule with excess electron character is extremely important for promoting the application of excess electron compounds in the nonlinear optical (NLO) field. Here, we report external electric field (EEF) induced second-order NLO switch molecules of inorganic alkaline-earth alkalides, $M\left(N_{3}\right)_{6} \mathrm{Na}_{2}(\mathrm{M}=\mathrm{Mg}$ or $\mathrm{Ca}$ ). The centrosymmetric structure of $\mathrm{M}\left(\mathrm{NH}_{3}\right)_{6} \mathrm{Na}_{2}$ is destroyed in the presence of an EEF, and then a long-range charge transfer process occurs. It has been found that excess electrons are gradually transferred from one $\mathrm{Na}$ atom to the other $\mathrm{Na}$ atom through the inorganic metal cluster $\mathrm{M}\left(\mathrm{NH}_{3}\right)_{6}$. Finally, the excess electrons are completely located on one of the two $\mathrm{Na}$ atoms. In particular, the electronic contribution of the static first hyperpolarizability $\left(\beta_{0}^{e}\right)$ for $\mathrm{M}\left(\mathrm{NH}_{3}\right)_{6} \mathrm{Na}_{2}$ exhibits a large significant difference when the EEF is switched

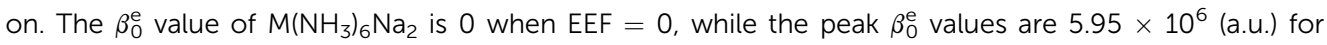
$\mathrm{Mg}\left(\mathrm{NH}_{3}\right)_{6} \mathrm{Na}_{2}\left(\mathrm{EEF}=58 \times 10^{-4}\right.$ (a.u.)) and $1.83 \times 10^{7}$ (a.u.) for $\mathrm{Ca}\left(\mathrm{NH}_{3}\right)_{6} \mathrm{Na}_{2}\left(\mathrm{EEF}=53 \times 10^{-4}\right.$ (a.u.)). This work demonstrates that the compounds $\mathrm{M}\left(\mathrm{NH}_{3}\right)_{6} \mathrm{Na}_{2}$ can serve as potential candidates for NLO switches.
\end{abstract}

Received 2nd April 2019

Accepted 14th May 2019

DOI: 10.1039/c9ra02470k

rsc.li/rsc-advances a suitable ligand, one of them acting as an anion and the other providing an excess of electrons. In addition, the first alkalineearth based alkalide $\mathrm{Ba}^{2+}\left(\mathrm{H}_{5}\right.$ Azacryptand $\left.[2.2 .2]^{-}\right) \mathrm{Na}^{-} \cdot 2 \mathrm{MeNH}_{2}$ was synthesized by Dye and his co-workers. ${ }^{34}$ Some alkalineearth alkalides with large NLO responses have been reported by Li et al., suggesting that an alkaline-earth with alkali atoms can also form an alkalide, where an alkaline-earth atom instead of an alkali atom provides the excess electrons. ${ }^{35}$

Stable magnesium and calcium ammines are well known to exhibit new and interesting properties. The inorganic metal cluster $\mathrm{Ca}\left(\mathrm{NH}_{3}\right)_{6}$ can be obtained by dissolving calcium in ammonia and its structure has been determined by experimental methods. ${ }^{\mathbf{3 6 - 4 0}}$ However, inorganic magnesium ammine $\mathrm{Mg}\left(\mathrm{NH}_{3}\right)_{6}$ has not been obtained so far. ${ }^{41}$ Nevertheless, with the existence of $\mathrm{Cl}^{-}$counterions, $\mathrm{Mg}\left(\mathrm{NH}_{3}\right)_{6} \mathrm{Cl}_{2}$ can be obtained. ${ }^{42-46}$ Li's group ${ }^{35}$ used $\mathrm{M}\left(\mathrm{NH}_{3}\right)_{6}(\mathrm{M}=\mathrm{Mg}, \mathrm{Ca})$ to theoretically design a series of novel alkalide molecules with double alkali anions $\mathrm{M}\left(\mathrm{NH}_{3}\right)_{6} \mathrm{Na}_{2}$ and they found that those compounds had large static first hyperpolarizability (electronic contribution $\beta_{0}^{\mathrm{e}}$ ) values ranging from 0 to $1.23 \times 10^{5}$ (a.u.). It was noticed that one of the isomers with centrosymmetry (with $D_{3 \mathrm{~d}}$ point group) of

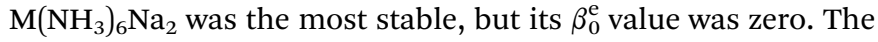
isomers with centrosymmetry $\mathrm{M}\left(\mathrm{NH}_{3}\right)_{6} \mathrm{Na}_{2}$ may be considered as potential NLO switches by breaking their symmetry with external stimulation, i.e. light irradiation, ${ }^{47}$ redox reaction, ${ }^{48} \mathrm{pH}$ variation, ion recognition, ${ }^{49}$ external electric field (EEF), and so on. ${ }^{19,20,50}$

On the one hand, among the above-mentioned external stimulators, EEF plays an important role in chemistry. For instance, Nakano et al. have shown that singlet diradical
${ }^{a}$ Key Laboratory of Theoretical Chemistry of Environment, Ministry of Education, School of Chemistry \& Environment of South China Normal University, Guangzhou 510006, People's Republic of China. E-mail: gu@scnu.edu.cn

${ }^{b}$ Department of Applied Chemistry, Institute of Molecular Science and Center for Interdisciplinary Molecular Science, National Chiao-Tung University, Hsinchu 30010, Taiwan

$\dagger$ Electronic supplementary information (ESI) available. See DOI: 10.1039/c9ra02470k 
molecules induced by EEF can produce giant static second hyperpolarizability. ${ }^{51,52}$ Bai et al. suggested that benzene has a large $\beta_{0}^{\mathrm{e}}$ value after the centrosymmetric structure has been broken by switching on a large EEF. ${ }^{53}$ Sun et al. demonstrated that the $\beta_{0}^{\mathrm{e}}$ value of superatom compounds can be greatly improved by 4790 times by imposing an EEF along the direction of charge transfer. ${ }^{54}$ Furthermore, EEF is also used to probe other properties, such as the $\Pi$ stacking interaction, ${ }^{55}$ proton transfer, ${ }^{56}$ metal-ligand bonding, chemical reactions etc. ${ }^{57}$

On the other hand, NLO switches with a large difference in NLO properties in the presence of external stimulator triggering have attracted more and more attention in recent years, ${ }^{19,20,50}$ because of their excellent potential applications in signal processing, data storage and optical frequency converters etc..$^{3-9}$ In the presence of EEF triggering, NLO switches of the organic electride molecule $\mathrm{K}(1) \cdots$ calix[4]pyrrole $\cdots \mathrm{K}(2)$ with $\beta_{0}^{\mathrm{e}}$ values ranging from $0\left(\mathrm{EEF}=0\right.$ (a.u.)) to $3.147 \times 10^{6}$ (a.u.) $(\mathrm{EEF}=8 \times$ $10^{-4}$ (a.u.)) and the all-metal electride molecules $\mathrm{e}^{-}+$ $\mathrm{M}^{2+}\left(\mathrm{Ni} @ \mathrm{~Pb}_{12}\right)^{2-} \mathrm{M}^{2+}+\mathrm{e}^{-}(\mathrm{M}=\mathrm{Be}, \mathrm{Mg}$ or $\mathrm{Ca})$ with $\beta_{0}^{\mathrm{e}}$ values ranging from $0\left(\mathrm{EEF}=0\right.$ (a.u.)) to $2.2 \times 10^{6}$ (a.u.) $(\mathrm{EEF}=30 \times$ $10^{-4}$ (a.u.)), as well as $\mathrm{Be}_{6} \mathrm{Li}_{8}$ and $\mathrm{Be}_{6} \mathrm{Li}_{14}$, were reported by $\mathrm{Li}$ and Hou et al. ${ }^{19,20,50}$

It is worth noticing that the above-mentioned NLO molecular switches are all electride molecules. ${ }^{\mathbf{1 9 , 2 0 , 5 0}}$ To the best of our knowledge, NLO switch molecules of an inorganic alkalineearth alkalide have not been reported yet. Obviously, exploring new NLO switches with excess electrons is extremely necessary for promoting excess electron applications in the NLO field, which is the target of this work. With this motivation, we theoretically investigate the effects of EEF on the geometries, molecular orbitals and NLO properties of previously reported ${ }^{35}$ novel alkaline-earth alkalide molecules $\mathrm{M}\left(\mathrm{NH}_{3}\right)_{6} \mathrm{Na}_{2}(\mathrm{M}=\mathrm{Mg}$, Ca) (see Fig. 1) in this work.

\section{Computational details}

All quantum chemistry calculations were executed by the Gaussian16 program package (revision B.01). ${ }^{58}$ The Coulombattenuated hybrid exchange-correlation functional CAMB3LYP has been proposed ${ }^{59,60}$ and successfully applied to calculate (hyper)polarizabilities for charge transfer systems..$^{\mathbf{2 0 , 3 5 , 6 1 - 6 5}}$ What is more, this method has been confirmed to give a better performance for calculating hyperpolarizability in the presence of EEF ${ }^{19}$ Furthermore, this functional can also provide molecular geometries close to experimental geometrical parameters. ${ }^{66}$ Therefore, geometrical optimization, frequency calculation, natural population analysis charge, interaction energy, electronic contributions of the polarizability and the static first hyperpolarizability were performed at the CAMB3LYP/6-311++G(2d,2p) level. ${ }^{67}$ The oscillator strength of the crucial excited state $\left(f_{0}\right)$, the excited energy of the crucial excited state $(\Delta E)$, and the difference in transition dipole moment between the ground state and the crucial excited state $(\Delta \mu)$ were calculated at the TD-CAM-B3LYP/6-311++G(2d,2p) level. ${ }^{68}$ It should be mentioned that $f_{0}$ and $\Delta \mu$ were obtained with Gaussian16, while $\Delta \mu$ was obtained with the free and open source Multiwfn program package (revision 3.6). ${ }^{69}$

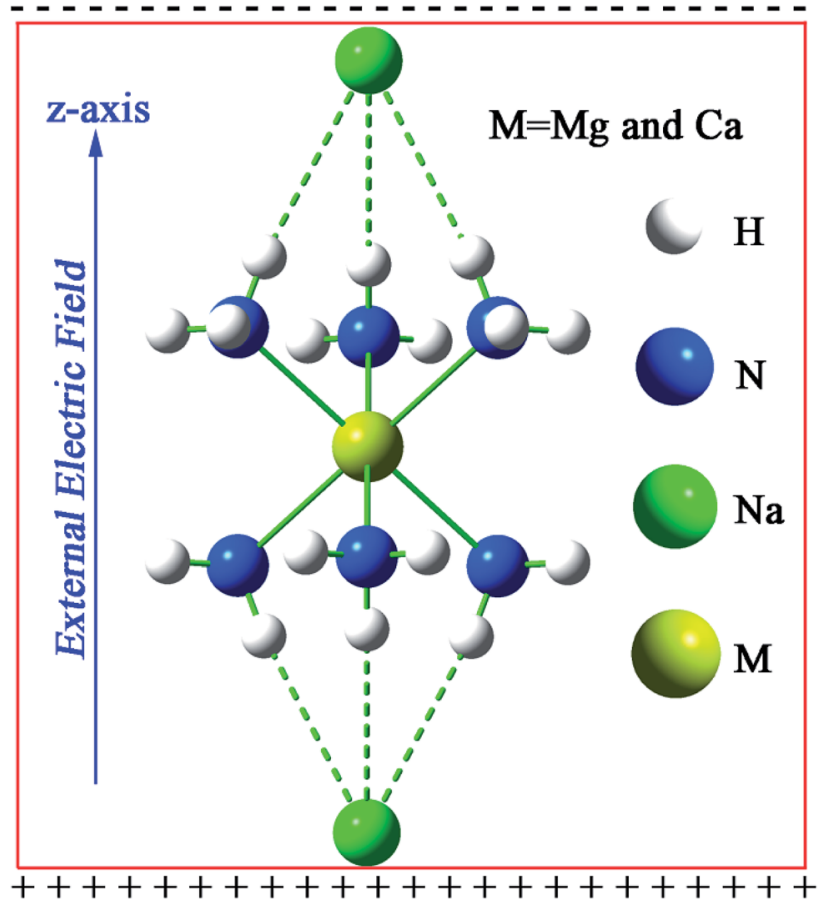

Fig. 1 The optimized geometrical structure of $M\left(N_{3}\right)_{6} \mathrm{Na}_{2}(\mathrm{M}=\mathrm{Mg}$ or Ca) at the CAM-B3LYP/6-311++G(2d,2p) level.

The interaction energies $\left(E_{\mathrm{int}}\right)$ are defined by eqn (1):

$$
E_{\text {int }}=E_{\mathrm{M}\left(\mathrm{NH}_{3}\right)_{6} \mathrm{Na}_{2}}-E_{\left(\mathrm{NH}_{3}\right)_{6} \mathrm{Na}_{2}}-E_{\mathrm{Na}_{2}}
$$

where $E_{\mathrm{M}\left(\mathrm{NH}_{3}\right)_{6} \mathrm{Na}_{2}}, E_{\left(\mathrm{NH}_{3}\right)_{6} \mathrm{Na}_{2}}$ and $E_{\mathrm{Na}_{2}}$ correspond to the energies of $\mathrm{M}\left(\mathrm{NH}_{3}\right)_{6} \mathrm{Na}_{2},\left(\mathrm{NH}_{3}\right)_{6} \mathrm{Na}_{2}$ and $\mathrm{Na}_{2}$.

The electronic contributions of the polarizability $\alpha^{\mathrm{e}}$ and the static first hyperpolarizability $\beta_{0}^{\mathrm{e}}$ are defined by eqn (2)-(4):

$$
\begin{gathered}
\alpha^{\mathrm{e}}=\frac{1}{3}\left(\alpha_{x x}+\alpha_{y y}+\alpha_{z z}\right) \\
\beta_{0}^{\mathrm{e}}=\left(\beta_{x}{ }^{2}+\beta_{y}{ }^{2}+\beta_{z}{ }^{2}\right)^{1 / 2}
\end{gathered}
$$

where

$$
\beta_{i}=\left(\beta_{i i i}+\beta_{i j j}+\beta_{i k k}\right), i, j, k=x, y, z
$$

\section{Results and discussion}

\subsection{EEF effects on geometries}

The equilibrium geometries of $\mathrm{M}\left(\mathrm{NH}_{3}\right)_{6} \mathrm{Na}_{2}(\mathrm{M}=\mathrm{Mg}$ or Ca) were obtained at the CAM-B3LYP/6-311++G(2d,2p) level and are depicted in Fig. 1. It should be noted that the direction of the imposed EEF is along the $z$-axis with a magnitude of 0 to $68 \times$ $10^{-4}$ (a.u.). If the strength of the imposed EEF is larger than $63 \times$ $10^{-4}$ (a.u.), the geometry of $\mathrm{Mg}\left(\mathrm{NH}_{3}\right)_{6} \mathrm{Na}_{2}$ will be destroyed, whereas, if EEF is larger than $68 \times 10^{-4}$ (a.u.), the geometry of $\mathrm{Ca}\left(\mathrm{NH}_{3}\right)_{6} \mathrm{Na}_{2}$ will be destroyed. Given that $\mathrm{Ca}\left(\mathrm{NH}_{3}\right)_{6} \mathrm{Na}_{2}$ $\left(-37.43 \mathrm{kcal} \mathrm{mol}^{-1}\right)$ shows a larger interaction compared with 


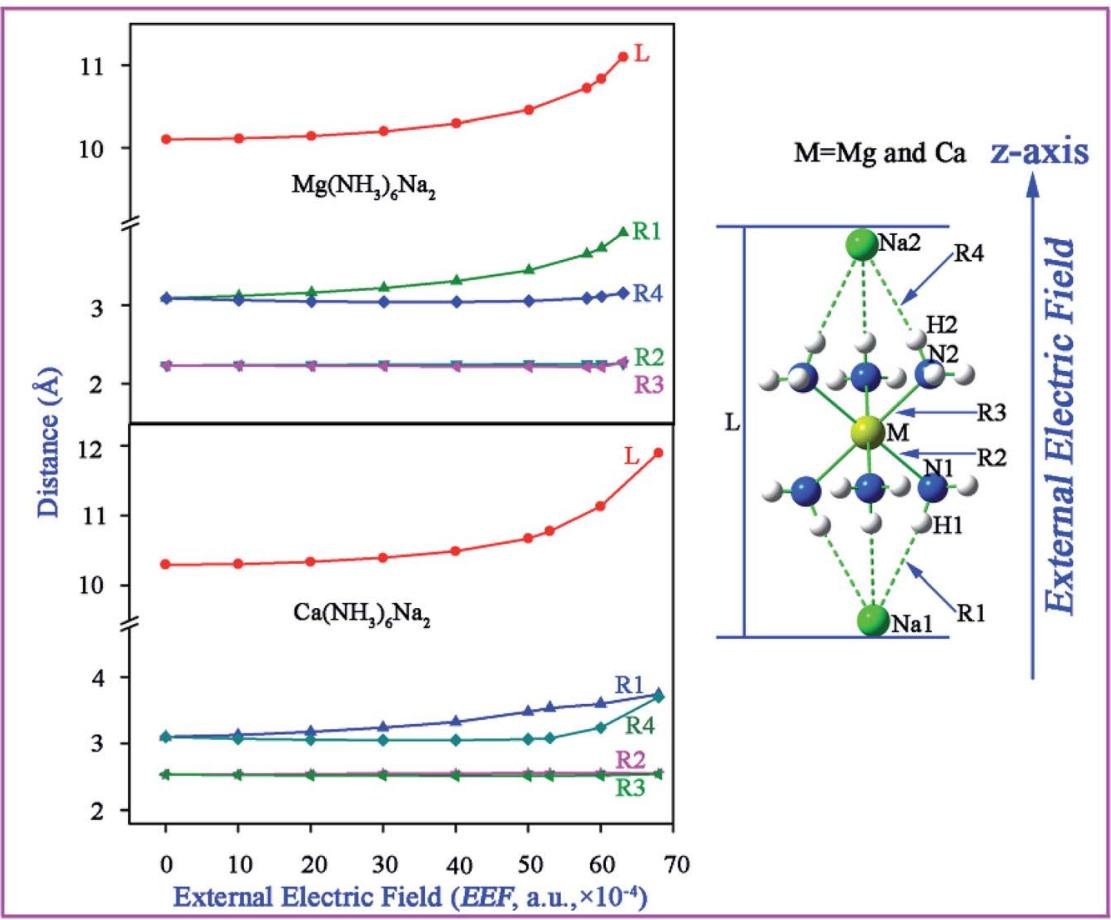

Fig. 2 The geometrical parameters $(\AA \AA)$ with different magnitudes of the external electric field (EEF, a.u., $\left.10^{-4}\right)$ for $M\left(\mathrm{NH}_{3}\right)_{6} \mathrm{Na}_{2}(\mathrm{M}=\mathrm{Mg}$ or $\mathrm{Ca})$ at the CAM-B3LYP/6-311++G(2d,2p) level.

$\mathrm{Mg}\left(\mathrm{NH}_{3}\right)_{6} \mathrm{Na}_{2}(-35.02 \mathrm{kcal})$ in the absence of EEF, the largest EEF thresholds are different. The point group of $\mathrm{M}\left(\mathrm{NH}_{3}\right)_{6} \mathrm{Na}_{2}$ will be changed from $D_{3 \mathrm{~d}}(\mathrm{EEF}=0)$ to $C_{3 \mathrm{~V}}(\mathrm{EEF} \neq 0)$. For a good visualization of the variable relationships between geometrical parameters and EEF, they are plotted in Fig. 2, and the related geometrical parameters have been collected in Tables S1 and S2.†
From Fig. 2, for both $\mathrm{Mg}\left(\mathrm{NH}_{3}\right)_{6} \mathrm{Na}_{2}$ and $\mathrm{Ca}\left(\mathrm{NH}_{3}\right)_{6} \mathrm{Na}_{2}$, one can see that the distance $R 1(\mathrm{Na} 1-\mathrm{H} 1)$ is equal to $R 4(\mathrm{Na} 2-\mathrm{H} 2)$, and $R 2(\mathrm{~N} 1-\mathrm{Mg})$ is equal to $R 3(\mathrm{~N} 2-\mathrm{Mg})$ when $\mathrm{EEF}=0$. While, if EEF is not equal to $0, R 1 \neq R 4, R 2 \approx R 3$ and $L(\mathrm{Na} 1-\mathrm{Na} 2)$ is elongated. It should be noticed that the variation in $L, R 1$, and $R 4$ is small when EEF is less than $40 \times 10^{-4}$ (a.u.). But, $L, R 1$ and

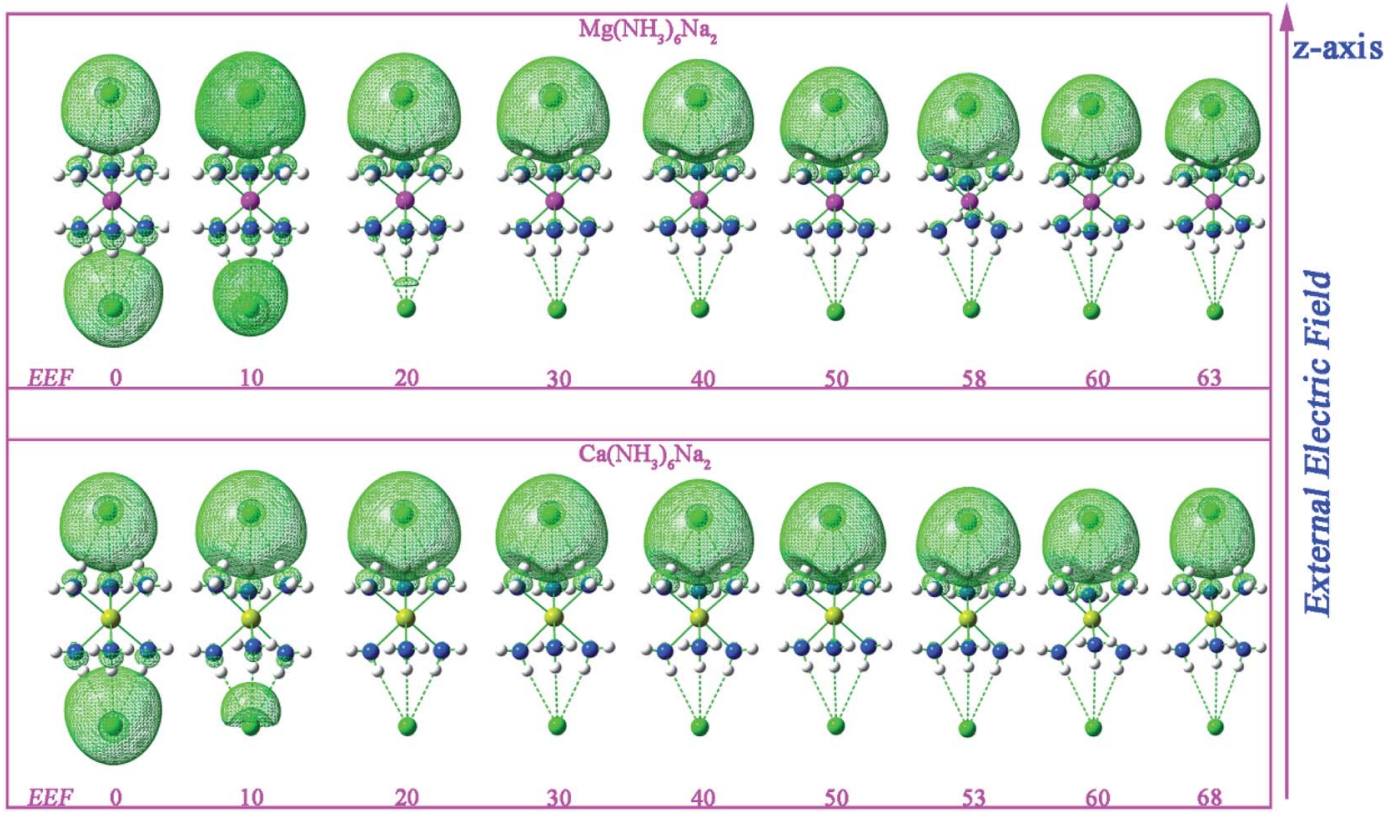

Fig. 3 The highest occupied molecular orbital $(\mathrm{HOMO})$ with different magnitudes of external electric field $\left(\mathrm{EEF}, \mathrm{a} . \mathrm{u} ., 10^{-4}\right)$ for $\mathrm{M}\left(\mathrm{NH}_{3}\right)_{6} \mathrm{Na}_{2}(\mathrm{M}=$ Mg or $\mathrm{Ca})$ at the CAM-B3LYP/6-311++G(2d,2p) level. 


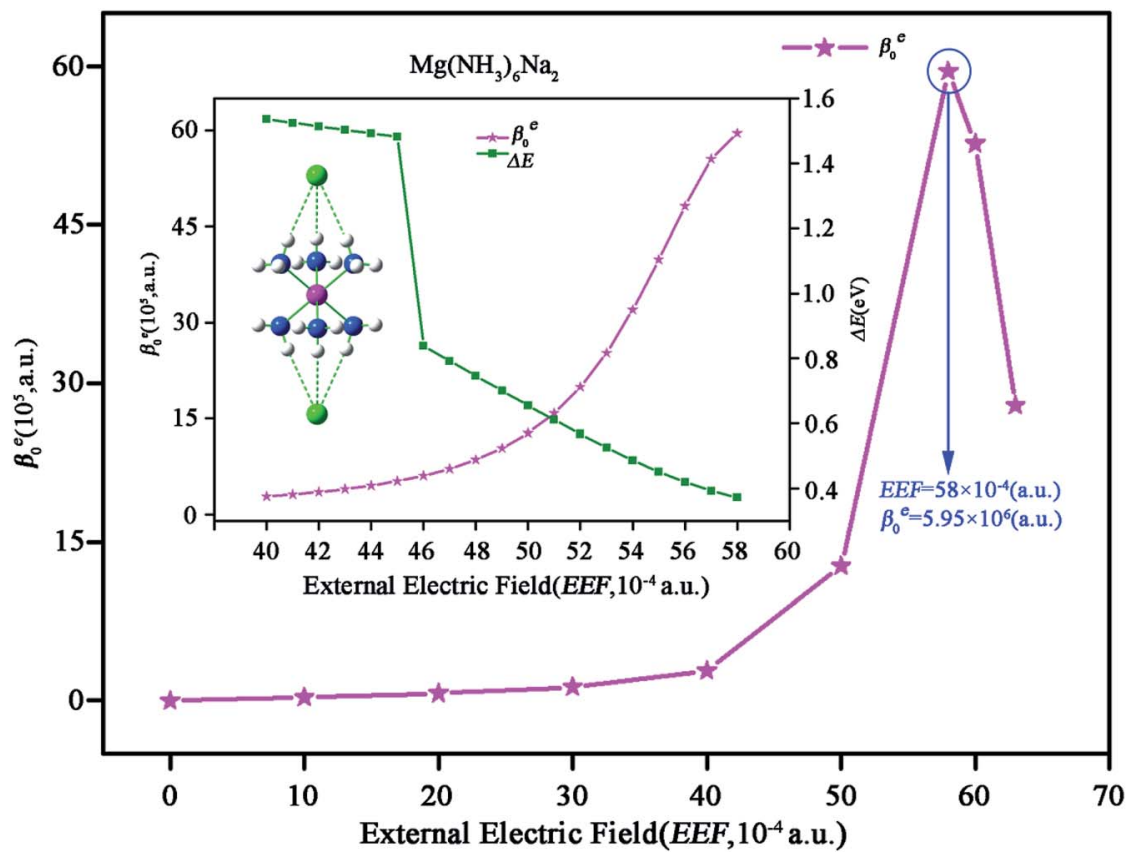

Fig. 4 The electronic contribution of the static first hyperpolarizability $\left(\beta_{0}^{\mathrm{e}}, \mathrm{a} . \mathrm{u}.\right)$ and the excited energy with different magnitudes of external electric field (EEF, a.u., $10^{-4}$ ) for $\mathrm{Mg}\left(\mathrm{NH}_{3}\right)_{6} \mathrm{Na}_{2}$ at the CAM-B3LYP/6-311++G(2d,2p) level.

$R 4$ are all drastically elongated when EEF is greater than $50 \times$ $10^{-4}$ (a.u.). In terms of an electro-optical device, it is expected that the geometry should retain its integrity. Therefore, EEF switches on the range from 0 to $40 \times 10^{-4}$ (a.u.) for $\mathrm{Mg}\left(\mathrm{NH}_{3}\right)_{6} \mathrm{Na}_{2}$ and $\mathrm{Ca}\left(\mathrm{NH}_{3}\right)_{6} \mathrm{Na}_{2}$, which is conducive to the development of a reversible switch.

\subsection{EEF effects on the highest occupied molecular orbitals}

The highest occupied molecular orbitals (HOMOs) (see Fig. 3) of $\mathrm{M}\left(\mathrm{NH}_{3}\right)_{6} \mathrm{Na}_{2}(\mathrm{M}=\mathrm{Mg}$ or $\mathrm{Ca})$ clearly display that the electron cloud is mainly distributed on the two Na atoms or one of two $\mathrm{Na}$ atoms, which suggests that $\mathrm{M}\left(\mathrm{NH}_{3}\right)_{6} \mathrm{Na}_{2}$ compounds have some excess electrons. In addition, the charges by the natural

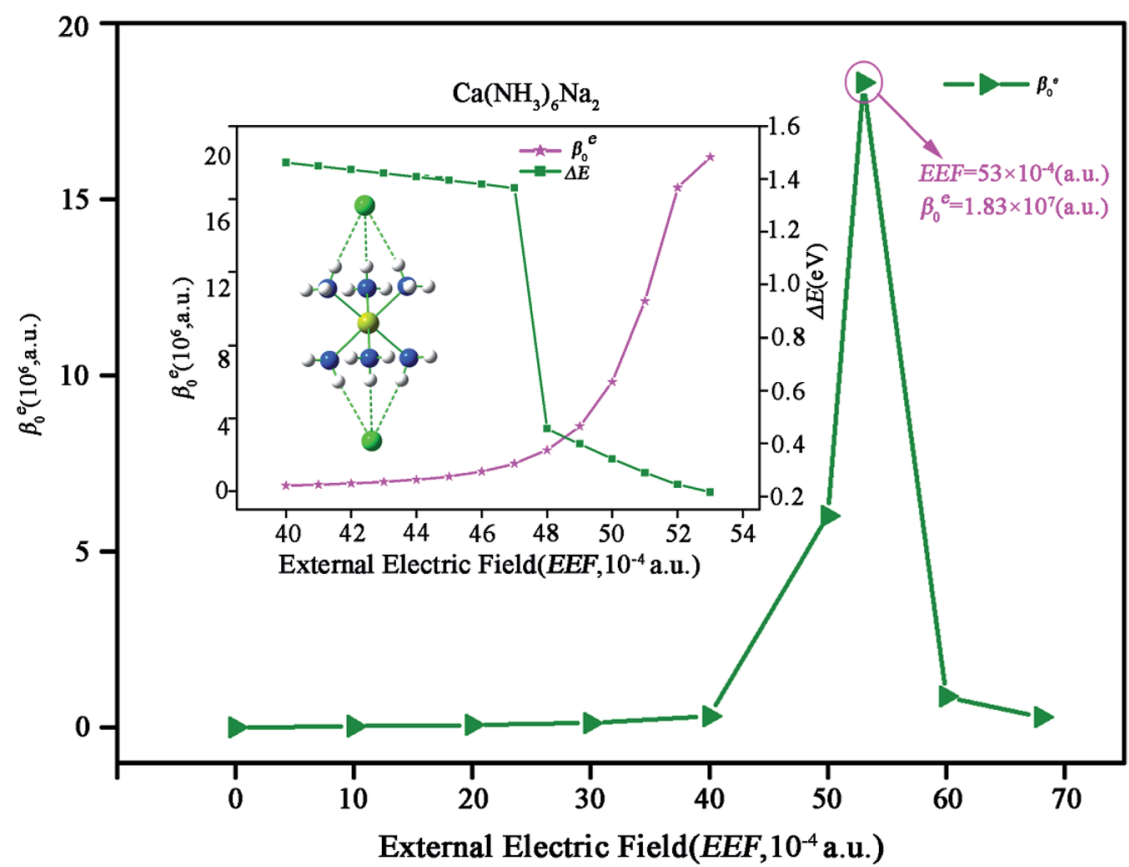

Fig. 5 The electronic contribution of the static first hyperpolarizability $\left(\beta_{0}^{\mathrm{e}}, \mathrm{a}\right.$.u. $)$ and the excited energy with different magnitudes of external electric field (EEF, a.u., $10^{-4}$ ) for $\mathrm{Ca}\left(\mathrm{NH}_{3}\right)_{6} \mathrm{Na}_{2}$ at the CAM-B3LYP/6-311++G(2d,2p) level. 

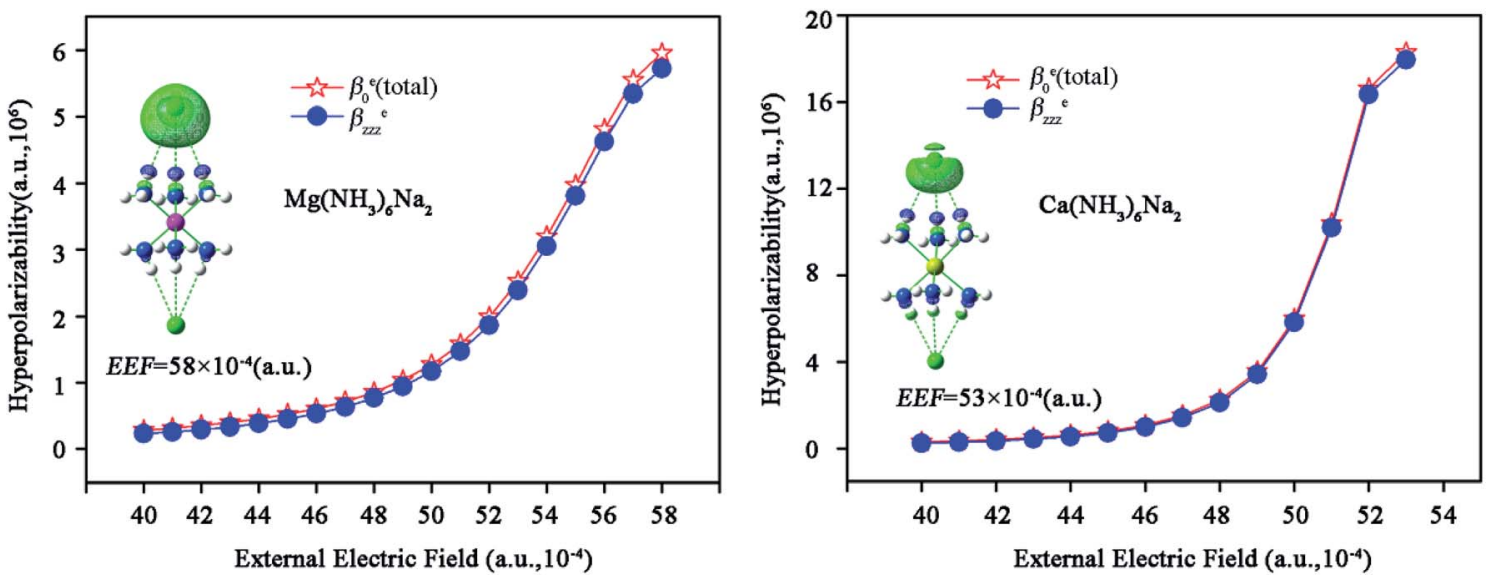

Fig. 6 Diagrams of hyperpolarizability density $-\rho_{z z}^{(2)}\left(E E F=58 \times 10^{-4}\right.$ for $\mathrm{Mg}\left(\mathrm{NH}_{3}\right)_{6} \mathrm{Na}_{2}$ and $\mathrm{EEF}=53 \times 10^{-4}$ for $\left.\mathrm{Ca}\left(\mathrm{NH}_{3}\right)_{6} \mathrm{Na}_{2}\right)$ and the relationships between $\beta_{z z z}^{\mathrm{e}}$ and the external electric field.

population analysis on $\mathrm{Na}$ atoms are negative $(-0.695$ to $-0.776|e|$ for $\mathrm{M}=\mathrm{Mg},-0.787$ to $-1.055|e|$ for $\mathrm{M}=\mathrm{Ca}$, see Table S3†), which further suggests that $\mathrm{M}\left(\mathrm{NH}_{3}\right)_{6} \mathrm{Na}_{2}$ compounds exhibit an alkalide character. From Fig. 3, one can see that when $\mathrm{EEF}=0$, the two excess electrons are distributed on the two Na atoms and exhibit centrosymmetry. The excess electrons are gradually transferred from one $\mathrm{Na}$ to the other $\mathrm{Na}$ atom with an increase in the EEF strength, resulting in the symmetry of the HOMOs for $\mathrm{M}\left(\mathrm{NH}_{3}\right)_{6} \mathrm{Na}_{2}$ being broken. When $\mathrm{EEF}>20 \times 10^{-4}$ (a.u.), the excess electrons located on one of the two $\mathrm{Na}$ atoms (the electric cloud of the large part is excess electrons of $\mathrm{Na}$, the electronic cloud of the small part is the lone pair of $\mathrm{N}$ atoms of the $\mathrm{NH}_{3}$ clusters), which demonstrates that a long-range charge transfer process is occurring through the inorganic metal cluster $\mathrm{M}\left(\mathrm{NH}_{3}\right)_{6}$ and this process may bring about a large NLO response.

\subsection{EEF effects on nonlinear optical properties}

The $\beta_{0}^{\mathrm{e}}$ values of $\mathrm{M}\left(\mathrm{NH}_{3}\right)_{6} \mathrm{Na}_{2}(\mathrm{M}=\mathrm{Mg}$ or $\mathrm{Ca})$ with and without EEF were calculated. To better visualize the results, the relationships between the $\beta_{0}^{\mathrm{e}}$ values of $\mathrm{M}\left(\mathrm{NH}_{3}\right)_{6} \mathrm{Na}_{2}$ and EEF have been plotted in Fig. 4 and 5 .

As shown in Fig. 4, the $\beta_{0}^{\mathrm{e}}$ of $\mathrm{Mg}\left(\mathrm{NH}_{3}\right)_{6} \mathrm{Na}_{2}$ first increases to the peak value of $5.95 \times 10^{6}$ (a.u.) for $E E F=58 \times 10^{-4}$ (a.u.), and then rapidly reduces to $2.79 \times 10^{6}$ (a.u.) for $\mathrm{EEF}=63 \times$ $10^{-4}$ (a.u.), indicating that the $\beta_{0}^{\mathrm{e}}$ value exhibits a large difference without and with EEF. It should be noticed that the $\beta_{0}^{\mathrm{e}}$ value of $\mathrm{Mg}\left(\mathrm{NH}_{3}\right)_{6} \mathrm{Na}_{2}$ slowly increases when EEF is less than $40 \times 10^{-4}$ (a.u.), but $\beta_{0}^{\mathrm{e}}$ greatly increases when the EEF is between $40 \times 10^{-4}$ and $58 \times 10^{-4}$ (a.u.). Fig. 4 clearly displays that the $\beta_{0}^{\mathrm{e}}$ value sharply increases from $2.84 \times 10^{5}$ (a.u.) to 5.95 $\times 10^{6}$ (a.u.) when EEF is in the range of $40 \times 10^{-4}$ to $58 \times 10^{-4}$ (a.u.). Therefore, we focus our attention on variation in $\beta_{0}^{\mathrm{e}}$ over this range of EEF. The $\beta_{0}^{\mathrm{e}}$ value of $\mathrm{Mg}\left(\mathrm{NH}_{3}\right)_{6} \mathrm{Na}_{2}$ for this range of EEF was recalculated (EEF with a step size $1 \times 10^{-4}$ (a.u.)) and the results are plotted in Fig. 4 (inset). The $\beta_{0}^{\mathrm{e}}$ of $\mathrm{Mg}\left(\mathrm{NH}_{3}\right)_{6} \mathrm{Na}_{2}$ slowly increases when EEF is in the range between $40 \times 10^{-4}$ and $45 \times 10^{-4}$ (a.u.), and $\beta_{0}^{\mathrm{e}}$ increases significantly when EEF is within the range from $46 \times 10^{-4}$ to $58 \times 10^{-4}$ (a.u.).
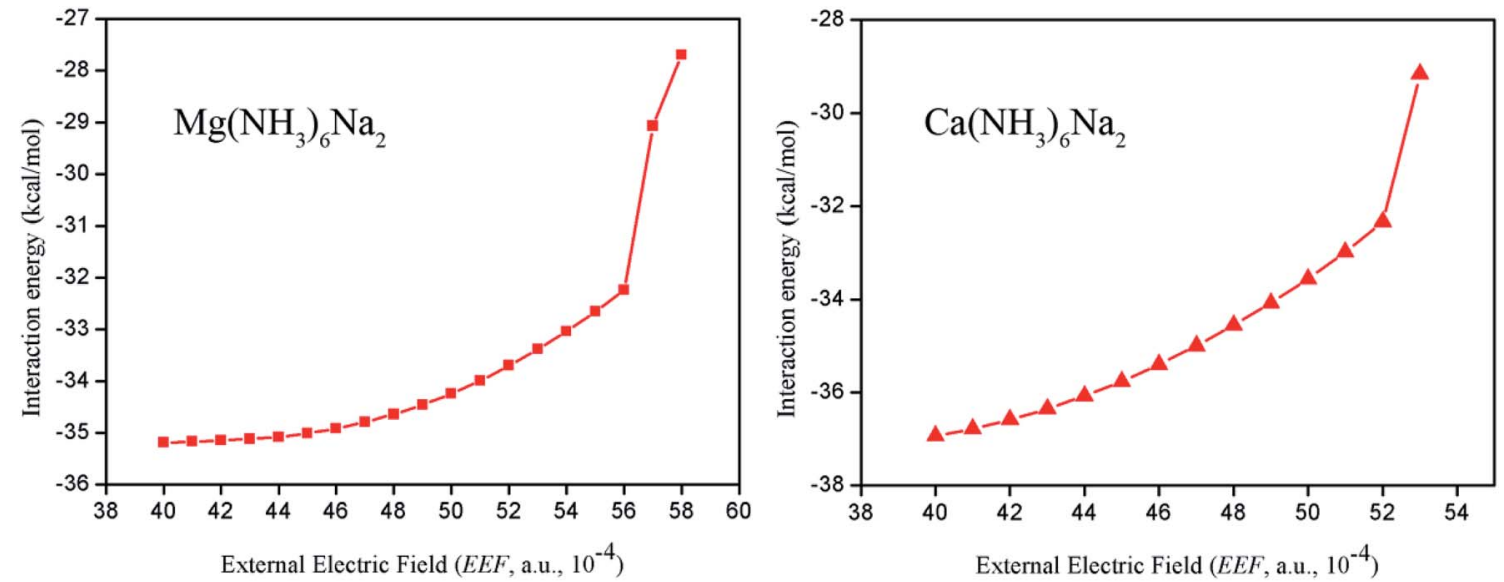

Fig. 7 The interaction energy between $M\left(\mathrm{NH}_{3}\right)_{6}(\mathrm{M}=\mathrm{Mg}$ or $\mathrm{Ca})$ and $\mathrm{Na}$ atoms under different external electric fields $\left(\mathrm{EEF}\right.$, a.u., $\left.10^{-4}\right)$ for $\mathrm{Ca}\left(\mathrm{NH}_{3}\right)_{6} \mathrm{Na}_{2}$ at the CAM-B3LYP/6-311++G(2d,2p) level. 
To better understand the change in $\beta_{0}^{\mathrm{e}}$ with the EEF switched on, a simplified two-level calculation is performed, ${ }^{70}$

$$
\beta_{0}^{\mathrm{e}} \propto \frac{\Delta \mu \times f_{0}}{\Delta E^{3}}
$$

where $\Delta \mu, f_{0}$, and $\Delta E$ denote the difference in transition dipole moment between ground state and crucial excited state, the oscillator strength of the crucial excited state and the excited energy of the crucial excited state. From eqn (5), one can see that $\beta_{0}^{\mathrm{e}}$ depends on three quantities: $\Delta \mu, f_{0}$ and $\Delta E$. Obviously, $\Delta E$ is the decisive factor for $\beta_{0}^{\mathrm{e}}$, since $\beta_{0}^{\mathrm{e}}$ is proportional to the inverse of its cube. While, sometimes the other two factors also cannot be neglected. Thus, we provide criteria for choosing the crucial excited state using values of these three quantities. The related $\Delta \mu, f_{0}$, and $\Delta E$ values of the crucial excited state are collected in Table $\mathrm{S} 4, \dagger$ where one can clearly see a better inverse relationship between $\beta_{0}^{\mathrm{e}}$ and $\Delta E$, which is plotted in Fig. 4 (inset). To be specific, $\Delta E$ exhibits a decreasing trend with increasing EEF, which demonstrates why $\beta_{0}^{\mathrm{e}}$ increases with increasing EEF. In addition, Fig. 4 also displays that $\mathrm{Mg}\left(\mathrm{NH}_{3}\right)_{6} \mathrm{Na}_{2}$ holds high excited energies (1.4816 eV to $1.5356 \mathrm{eV}$ ) when EEF is between $40 \times 10^{-4}$ and $45 \times 10^{-4}$ (a.u.), but low excited energies $(0.3722 \mathrm{eV}$ to $0.8384 \mathrm{eV})$ when EEF is between $46 \times 10^{-4}$ and 58 $\times 10^{-4}$ (a.u.). The reason for this is that the crucial excited states are located at high excited state $\mathrm{S} 6$ for EEF ranging from $40 \times$ $10^{-4}$ to $45 \times 10^{-4}$ (a.u.) and low excited state S1 for EEF ranging from $40 \times 10^{-4}$ to $45 \times 10^{-4}$ (a.u.). This explains why $\beta_{0}^{\mathrm{e}}$ slowly increases at first, and then quickly increases when EEF is within the range of $40 \times 10^{-4}$ to $58 \times 10^{-4}$ (a.u.). In addition, one can see from Fig. 4 that the $\beta_{0}^{\mathrm{e}}$ values rapidly decrease after presenting a maximum, which is due to $\Delta E$ increasing with increasing EEF; the excited energy increased to $1.6794 \mathrm{eV}$.

For the case of $\mathrm{Ca}\left(\mathrm{NH}_{3}\right)_{6} \mathrm{Na}_{2}$, from Fig. 5 one can clearly see that $\beta_{0}^{\mathrm{e}}$ value of $\mathrm{Ca}\left(\mathrm{NH}_{3}\right)_{6} \mathrm{Na}_{2}$ gradually increases to $3.11 \times 10^{5}$ (a.u.) when EEF is less than $40 \times 10^{-4}$ (a.u.), and then

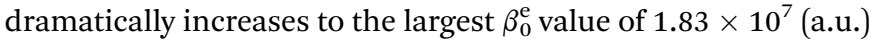
for $\mathrm{EEF}=53 \times 10^{-4}$ (a.u.), rapidly decreasing to $2.99 \times 10^{5}$ (a.u.) for $E E F=68 \times 10^{-4}$ (a.u.). Here, we mainly focus on discussing the variation in $\beta_{0}^{\mathrm{e}}$ with EEF ranging from $40 \times 10^{-4}$ to $53 \times 10^{-4}$ (a.u.). The corresponding $\beta_{0}^{\mathrm{e}}$ (EEF with a step size of $1 \times 10^{-4}$ (a.u.)) was calculated and is given in Fig. 5 (inset).

How can we understand the variation in $\beta_{0}^{\mathrm{e}}$ with changing EEF? It is likely that we will find some clues from eqn (4). Fig. 5 clearly shows the relationship between $\beta_{0}^{\mathrm{e}}$ and $\Delta E$. When EEF continuously increases, the $\beta_{0}^{\mathrm{e}}$ value of $\mathrm{Ca}\left(\mathrm{NH}_{3}\right)_{6} \mathrm{Na}_{2}$ increases with decreasing $\Delta E$ (1.4617 to $0.2155 \mathrm{eV})$. Furthermore, Fig. 5 also illustrates that $\Delta E$ dramatically decreases. The reason for this is that the crucial excited state goes from high excited state S6 for EEF ranging from $40 \times 10^{-4}$ to $47 \times 10^{-4}$ (a.u.) to low excited state $\mathrm{S} 1$ for EEF within in the range of $48 \times 10^{-4}$ to $53 \times$ $10^{-4}$ (a.u.), which explains why $\beta_{0}^{\mathrm{e}}$ increases slowly at first and then rapidly increases in this EEF range $\left(40 \times 10^{-4}\right.$ to $53 \times 10^{-4}$ (a.u.)). Therefore, $\Delta E$ is a decisive factor for the variation of $\beta_{0}^{\mathrm{e}}$ with changing EEF. Similarly, the $\beta_{0}^{\mathrm{e}}$ values dramatically decrease after exhibiting a peak value, owing to $\Delta E$ increasing with increasing EEF, which increased to $1.7838 \mathrm{eV}$.
In the above discussions, we have obtained a qualitative explanation for the relationship between $\beta_{z z z}^{\mathrm{e}}$ and the external electric field according to the simplified two-level equation. In order to obtain a quantitative explanation for this, hyperpolarizability density analysis is a good choice. ${ }^{71,72}$ Hyperpolarizability density $\rho$ is defined by the electronic density of a spatial point $r$ in the presence of an external field $F$, namely, by the Taylor expansion of energy with respect to an external field:

$$
\rho(r, F)=\rho^{(0)}(r)+\rho^{(1)}(r) F+\frac{1}{2} \rho^{(2)}(r) F^{(2)}+\frac{1}{6} \rho^{(3)}(r) F^{3}+\ldots
$$

From eqn (6), $\beta_{z z z}^{\mathrm{e}}$ can be obtained by the following formula:

$$
\beta_{z z z}^{\mathrm{e}}=\int-\rho_{z z}^{(2)}(r) \times r \mathrm{~d} r
$$

where

$$
\rho_{z z}^{(2)}(r)=\left.\frac{\partial^{2} \rho(r)}{\partial F_{z}^{2}}\right|_{F=0}
$$

The first hyperpolarizability density maps (see Fig. 6) are plotted with the free and open source Multiwfn program. ${ }^{69}$ One can see from Fig. 6 that the electronic contribution on the first hyperpolarizability mainly originates from the upper $\mathrm{Na}$ atom

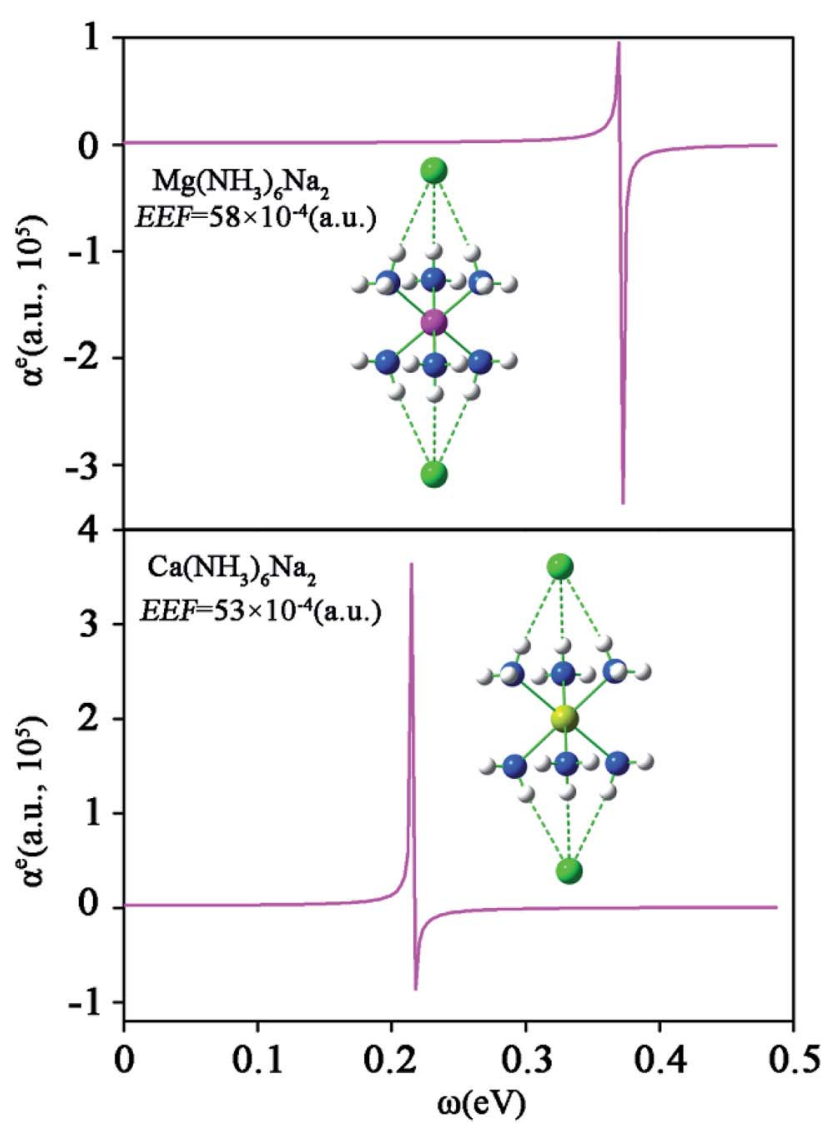

Fig. 8 The electronic contribution of the polarizability dispersion curve for $\mathrm{M}\left(\mathrm{NH}_{3}\right)_{6} \mathrm{Na}_{2}$ (M = Mg or $\mathrm{Ca}$ ) at the CAM-B3LYP/6$311++G(2 d, 2 p)$ level. 
Table 1 The electron $\left(\beta_{0}^{\mathrm{e}}\right.$, a.u. $)$ and nuclear relaxation $\left(\beta_{0}^{\mathrm{nr}}\right.$, a.u.) contributions of the static first hyperpolarizability of $\mathrm{M}\left(\mathrm{NH}_{3}\right)_{6} \mathrm{Na}{ }_{2}$ at the $\mathrm{CAM}-$ B3LYP/6-311++G(2d,2p) level

\begin{tabular}{|c|c|c|c|c|c|}
\hline \multirow[b]{2}{*}{$\operatorname{EEF}\left(\right.$ a.u., $\times 10^{-4}$ ) } & \multicolumn{2}{|c|}{$\mathrm{Mg}\left(\mathrm{NH}_{3}\right)_{6} \mathrm{Na}_{2}$} & \multirow[b]{2}{*}{ EEF (a.u., $\times 10^{-4}$ ) } & \multicolumn{2}{|c|}{$\underline{\mathrm{Ca}\left(\mathrm{NH}_{3}\right)_{6} \mathrm{Na}_{2}}$} \\
\hline & $\beta_{0}^{\mathrm{e}}$ & $\beta_{0}^{\mathrm{nr}}$ & & $\beta_{0}^{\mathrm{e}}$ & $\beta_{0}^{\mathrm{nr}}$ \\
\hline
\end{tabular}

under high EEF. Furthermore, the values of $\beta_{z z z}^{\mathrm{e}}$ increase with increasing EEF, which explains why the total $\beta_{0}^{\mathrm{e}}$ values increase with increasing EEF.

For a good illustration of the performance of $\mathrm{M}\left(\mathrm{NH}_{3}\right)_{6} \mathrm{Na}_{2}(\mathrm{M}$ $=\mathrm{Mg}$ or $\mathrm{Ca}$ ) in a nonlinear optical switch, we further compared the electronic contribution of the first hyperpolarizability value between the current work and previous reports for a nonlinear optical switch. It was found that the inorganic alkaline-earth alkalides $\mathrm{M}\left(\mathrm{NH}_{3}\right)_{6} \mathrm{Na}_{2}(\mathrm{M}=\mathrm{Mg}$ or $\mathrm{Ca})$, with $\beta_{0}^{\mathrm{e}}$ values of 0 to 5.95 $\times 10^{6}$ (a.u.) and 0 to $1.83 \times 10^{7}$ (a.u.) for $\mathrm{Mg}\left(\mathrm{NH}_{3}\right)_{6} \mathrm{Na}_{2}$ and $\mathrm{Ca}\left(\mathrm{NH}_{3}\right)_{6} \mathrm{Na}_{2}$, respectively, show a better performance than organic electride $\mathrm{K}(1) \cdots$ calix[4]pyrrole $\cdots \mathrm{K}(2)$ with a $\beta_{0}^{\mathrm{e}}$ of 0 to $3.15 \times 10^{6}$ (a.u.), ${ }^{19}$ all-metal electride $\mathrm{e}^{-}+\mathrm{M}^{2+}\left(\mathrm{Ni} @ \mathrm{~Pb}_{12}\right)^{2-} \mathrm{M}^{2+}+$ $\mathrm{e}^{-}(\mathrm{M}=\mathrm{Be}, \mathrm{Mg}$ or $\mathrm{Ca})$ with $\beta_{0}^{\mathrm{e}}$ ranging from 0 to $2.20 \times 10^{6}$ (a.u. $)^{20}$ or all-metal electride $\mathrm{Be}_{6} \mathrm{Li}_{8}$ with the largest $\beta_{0}^{\mathrm{e}}$ value of $5.54 \times 10^{4}$ (a.u.) and $\mathrm{Be}_{6} \mathrm{Li}_{14}$ with the largest $\beta_{0}^{\mathrm{e}}$ value $5.0 \times 10^{6}$ (a.u.). ${ }^{50}$ Furthermore, $\mathrm{M}\left(\mathrm{NH}_{3}\right)_{6} \mathrm{Na}_{2}$ also showed a better NLO performance than the organic compound benzene with the largest $\beta_{0}^{\mathrm{e}}$ value of $3.9 \times 10^{5}$ (a.u.) in the presence of EEF. ${ }^{53}$

Furthermore, some NLO switch molecules have been synthesized in the presence of external stimulator triggering: e.g. an acido-triggered second-order NLO switch photochromic cyclometallated platinum(II) complex, ${ }^{73}$ a temperature-induced symmetry-breaking phase transition NLO switch ${ }^{74}$ and so forth. Experimental investigations further demonstrate the possibility of the synthesis of a stimulator introduced NLO switch.

In terms of applications of nonlinear optical switches, stability is also an important issue. Thus, to characterize the stability of compounds with a high external electric field, we further calculated the interaction energy between $\mathrm{M}\left(\mathrm{NH}_{3}\right)_{6}(\mathrm{M}=$ $\mathrm{Mg}$ or $\mathrm{Ca}$ ) and $\mathrm{Na}$ atoms in the range of a high external electric field. The calculated results showed that the ranges of interaction energy for $\mathrm{Mg}\left(\mathrm{NH}_{3}\right)_{6} \mathrm{Na}_{2}$ and $\mathrm{Ca}\left(\mathrm{NH}_{3}\right)_{6} \mathrm{Na}_{2}$ are -27.70 to -35.19 and -29.17 to $-36.93 \mathrm{kcal} \mathrm{mol}^{-1}$ (see Fig. 7), respectively, which demonstrates that $\mathrm{M}\left(\mathrm{NH}_{3}\right)_{6} \mathrm{Na}_{2}(\mathrm{M}=\mathrm{Mg}$ or $\mathrm{Ca})$ compounds are stable over the range of a high external electric field. $\mathrm{Mg}\left(\mathrm{NH}_{3}\right)_{6} \mathrm{Na}_{2}$ still has a large interaction energy of -7.71 $\mathrm{kcal} \mathrm{mol}^{-1}$ under a working external electric field, it should be revised that $\mathrm{Mg}\left(\mathrm{NH}_{3}\right)_{6} \mathrm{Na}_{2}$ still has a large interaction energy $-27.71 \mathrm{kcal} \mathrm{mol}^{-1}$ under a working external electric field. Thus, this compound also is relatively stable under a working external electric field with the largest value of $\beta_{0}^{\mathrm{e}}$.

To better understand the frequency dependence behavior of $\mathrm{M}\left(\mathrm{NH}_{3}\right)_{6} \mathrm{Na}_{2}(\mathrm{M}=\mathrm{Mg}$ or $\mathrm{Ca})$, we further calculated the electronic contribution of the polarizability $\left(\alpha_{0}^{\mathrm{e}}\right)$ dispersion curve of $\mathrm{M}\left(\mathrm{NH}_{3}\right)_{6} \mathrm{Na}_{2}\left(\mathrm{EEF}=58 \times 10^{-4}\right.$ (a.u.) for $\mathrm{M}=\mathrm{Mg}$, EEF $=53 \times 10^{-4}$ (a.u.) for $\mathrm{M}=\mathrm{Ca}$ ) with an optical frequency $(\omega)$ ranging from 0 to $0.5 \mathrm{eV}$, and the relationships between $\alpha_{0}^{\mathrm{e}}$ and $\omega$ are plotted in Fig. 8. This clearly shows that there are pole points with their positions close to $0.3722 \mathrm{eV}$ and $0.2155 \mathrm{eV}$ for $\mathrm{Mg}\left(\mathrm{NH}_{3}\right)_{6} \mathrm{Na}_{2}$ and $\mathrm{Ca}\left(\mathrm{NH}_{3}\right)_{6} \mathrm{Na}_{2}$, respectively. When $\omega$ is calculated to be close to the pole points, it will generate a very large electronic contribution of dynamic (hyper)polarizabilities.

In addition, the nuclear relaxation contribution of the static first hyperpolarizability $\beta_{0}^{\text {nr }}$ also plays a key role in NLO properties. $^{75,76}$ Thus, we further calculated the $\beta_{0}^{\mathrm{nr}}$ of $\mathrm{M}\left(\mathrm{NH}_{3}\right)_{6} \mathrm{Na}_{2}$ by using the field induced coordinates (FICs) method which was proposed by Luis's group, and the results are given in Table 1. For more detailed information on FICs, readers are recommended to read ref. 77-79. One can clearly see that $\beta_{0}^{\text {nr }}$ exhibits a large contribution with $3.84 \times 10^{6}$ (a.u.) and $4.01 \times 10^{6}$ (a.u.) for $\mathrm{Mg}\left(\mathrm{NH}_{3}\right)_{6} \mathrm{Na}_{2}$ and $\mathrm{Ca}\left(\mathrm{NH}_{3}\right)_{6} \mathrm{Na}_{2}$, respectively, which indicates that the nuclear relaxation contribution to the NLO properties of $\mathrm{M}\left(\mathrm{NH}_{3}\right)_{6} \mathrm{Na}_{2}$ is also a significant component.

\section{Conclusions}

In this work, we have designed NLO switch molecules, $\mathrm{Mg}\left(\mathrm{NH}_{3}\right)_{6} \mathrm{Na}_{2}$ and $\mathrm{Ca}\left(\mathrm{NH}_{3}\right)_{6} \mathrm{Na}_{2}$, by a theoretical study. Our computational results demonstrate that the inorganic alkalineearth alkalide $\mathrm{M}\left(\mathrm{NH}_{3}\right)_{6} \mathrm{Na}_{2}(\mathrm{M}=\mathrm{Mg}$ or $\mathrm{Ca})$ can serve as a potential candidate for a NLO switch. The results highlight the following points:

(1) The centrosymmetric structure of $\mathrm{M}\left(\mathrm{NH}_{3}\right)_{6} \mathrm{Na}_{2}$ is destroyed in the presence of an EEF, and then a long-range transfer process occurs.

(2) The electronic contribution of the static first hyperpolarizability $\left(\beta_{0}^{\mathrm{e}}\right)$ is very sensitive to the EEF. The $\beta_{0}^{\mathrm{e}}$ exhibits a significant difference when the EEF is switched on. The peak $\beta_{0}^{\mathrm{e}}$ value is $5.95 \times 10^{6}$ (a.u.) for $\mathrm{Mg}\left(\mathrm{NH}_{3}\right)_{6} \mathrm{Na}_{2}$ and $83 \times 10^{7}$ (a.u.) for $\mathrm{Ca}\left(\mathrm{NH}_{3}\right)_{6} \mathrm{Na}_{2}$.

(3) The electronic contribution of the polarizability curve for $\mathrm{M}\left(\mathrm{NH}_{3}\right)_{6} \mathrm{Na}_{2}\left(\mathrm{EEF}=58 \times 10^{-4}\right.$ (a.u.) for $\mathrm{M}=\mathrm{Mg}, \mathrm{EEF}=53 \times$ $10^{-4}$ (a.u.) for $\mathrm{M}=\mathrm{Ca}$ ) with optical frequency ranging from 0 to $0.5 \mathrm{eV}$ was obtained. The pole points are $0.3722 \mathrm{eV}$ and $0.2155 \mathrm{eV}$ for $\mathrm{M}=\mathrm{Mg}$ and $\mathrm{M}=\mathrm{Ca}$, respectively.

(4) The nuclear relaxation contribution of the static first hyperpolarizability plays a key role in the NLO properties of $\mathrm{M}\left(\mathrm{NH}_{3}\right)_{6} \mathrm{Na}_{2}$.

In general, we hope that this work can provide a theoretical reference for designing NLO switches and motivate experimental chemists to synthesize them in the near future. 


\section{Conflicts of interest}

There are no conflicts to declare.

\section{Acknowledgements}

The authors are grateful for financial support from the National Key R\&D Program of China (Grant No. 2017YFB0203403). This work was also supported by the National Natural Science Foundation of China (Grant No. 21673085 and 21773075) and the Guangdong-Hong Kong Technology Cooperation Funding Scheme (Grant No. 2017A050506048). All authors thank Prof. Josep M. Luis of University of Girona for providing Field Induced Coordinates (FICs) code and thank Dr Hui-Min He of Jilin University for technology support with FICs.

\section{References}

1 P. A. Franken, A. E. Hill, C. W. Peters and G. Weinreich, Phys. Rev. Lett., 1961, 7, 118-119.

2 D. R. Kanis, M. A. Ratner and T. J. Marks, Design and construction of molecular assemblies with large secondorder optical nonlinearities. Quantum chemical aspects, Chem. Rev., 1994, 94, 195-242.

3 F. Meyers, S. R. Marder, B. M. Pierce and J. L. Brédas, Electric Field Modulated Nonlinear Optical Properties of DonorAcceptor Polyenes: Sum-Over-States Investigation of the Relationship between Molecular Polarizabilities (.alpha., .beta., and .gamma.) and Bond Length Alternation, J. Am. Chem. Soc., 1994, 116, 10703-10714.

4 M. Ja Lee, M. Piao, M. Y. Jeong, S. Hae Lee, K. Min Kang, S. J. Jeon, T. Gun Lim and B. Rae Cho, Novel azo octupoles with large first hyperpolarizabilities, J. Mater. Chem., 2003, 13, 1030-1037.

5 O. Ostroverkhova and W. E. Moerner, Organic photorefractives: mechanisms, materials, and applications, Chem. Rev., 2004, 104, 3267-3314.

6 S. Muhammad, H. L. Xu, R. L. Zhong, Z. M. Su, A. G. AlSehemic and A. Irfanc, Quantum chemical design of nonlinear optical materials by sp 2-hybridized carbon nanomaterials: issues and opportunities, J. Mater. Chem. C, 2013, 1, 5439-5449.

7 L. W. Chen, G. T. Yu, W. Chen, C. Y. Tu, X. G. Zhao and X. R. Huang, Constructing a mixed $\pi$-conjugated bridge to effectively enhance the nonlinear optical response in the Möbius cyclacene-based systems, Phys. Chem. Chem. Phys., 2014, 16, 10933-10942.

8 L. Wang, J. T. Ye, H. Chen, Z. Z. Chen, Y. Q. Qiu and H. M. Xie, A structure-property interplay between the width and height of cages and the static third order nonlinear optical responses for fullerenes: applying gamma density analysis, Phys. Chem. Chem. Phys., 2017, 19, 23222331.

9 M. Rajeshirke, M. C. Sreenath, S. Chitrambalam, I. H. Joe and N. Sekar, Enhancement of NLO Properties in OBO Fluorophores Derived from Carbazole-Coumarin
Chalcones Containing Carboxylic Acid at the N-Alykl Terminal End, J. Phys. Chem. C, 2018, 122, 14313-14325.

$10 \mathrm{~J}$. O. Morley, Calculated hyperpolarisabilities of polythiophenes, polyfurans and polypyrroles, J. Chem. Soc., Faraday Trans., 1991, 87, 3009-3013.

11 N. N. Ma, S. L. Sun, C. G. Liu, X. X. Sun and Y. Q. Qiu, Quantum Chemical Study of Redox-Switchable SecondOrder Nonlinear Optical Responses of $\mathrm{D}-\pi-\mathrm{A}$ System BNbpy and Metal Pt (II) Chelate Complex, J. Phys. Chem. A, 2011, 115, 13564-13572.

12 M. Nakano, R. Kishi, T. Nitta, T. Kubo, K. Nakasuji, K. K. K. Ohta, B. Champagne, E. Botek and K. Yamaguchi, Second hyperpolarizability $(\gamma)$ of singlet diradical system: dependence of $\gamma$ on the diradical character, J. Phys. Chem. $A, 2005,109,885-891$.

13 M. Nakano, R. Kishi, S. Ohta, H. Takahashi, T. Kubo, K. Kamada, K. Ohta, E. Botek and B. Champagne, Relationship between third-order nonlinear optical properties and magnetic interactions in open-shell systems: a new paradigm for nonlinear optics, Phys. Rev. Lett., 2007, 99, 033001.

14 M. Nakano and B. Champagne, Theoretical design of openshell singlet molecular systems for nonlinear optics, $J$. Phys. Chem. Lett., 2015, 6, 3236-3256.

15 W. Chen, Z. R. Li, D. Wu, Y. Li, C. C. Sun, F. L. Gu and Y. Aoki, Nonlinear Optical Properties of Alkalides Li+(calix [4]pyrrole)M- ( $\mathrm{M}=\mathrm{Li}, \mathrm{Na}$, and $\mathrm{K})$ : Alkali Anion Atomic Number Dependence, J. Am. Chem. Soc., 2006, 128, 10721073.

16 R. L. Zhong, H. L. Xu, Z. R. Li and Z. M. Su, Role of excess electrons in nonlinear optical response, J. Phys. Chem. Lett., 2015, 6, 612-619.

17 W. M. Sun, L. T. Fan, Y. Li, J. Y. Liu, D. Wu and Z. R. Li, On the potential application of superalkali clusters in designing novel alkalides with large nonlinear optical properties, Inorg. Chem., 2014, 53, 6170-6178.

18 B. Li, C. Xu, X. Xu, C. Y. Zhu and F. L. Gu, Remarkable nonlinear optical response of excess electron compounds: theoretically designed alkali-doped aziridine M-(C2NH5)n, Phys. Chem. Chem. Phys., 2017, 19, 23951-23959.

19 J. J. Wang, Z. J. Zhou, H. M. He, D. Wu, Y. Li, Z. R. Li and H. X. Zhang, An External Electric Field Manipulated Second-Order Nonlinear Optical Switch of an Electride Molecule: A Long-Range Electron Transfer Forms a Lone Excess Electron Pair and Quenches Singlet Diradical, J. Phys. Chem. C, 2016, 120, 13656-13666.

20 H. M. He, Y. Li, H. Yang, D. Yu, S. Y. Li, D. Wu, J. H. Hou, R. L. Zhong, Z. J. Zhou, F. L. Gu, J. M. Luis and Z. R. Li, Efficient External Electric Field Manipulated Nonlinear Optical Switches of All-Metal Electride Molecules with Infrared Transparency: Nonbonding Electron Transfer Forms an Excess Electron Lone Pair, J. Phys. Chem. C, 2017, 121, 958-968.

21 J. L. Dye, Electrides: from 1D Heisenberg chains to 2D pseudo-metals, Inorg. Chem., 1997, 36, 3816-3826. 
22 A. S. Ichimura, J. L. Dye, M. A. Camblor and L. A. Villaescusa, Toward inorganic electrides, J. Am. Chem. Soc., 2002, 124, 1170-1171.

23 S. Matsuishi, Y. Toda, M. Miyakawa, K. Hayashi, T. Kamiya, M. Hirano, I. Tanaka and H. Hosono, High-density electron anions in a nanoporous single crystal:[Ca24Al28O64]4+(4e-), Science, 2003, 301, 626-629.

24 M. J. Wagner and J. L. Dye in Molecular Recognition: Receptors for Cationic Guests, ed. G. W. Gokel, Pergamon, Oxford, UK, 1996, vol. 1, pp. 477-510.

25 J. L. Dye, Anionic electrons in electrides, Nature, 1993, 365, 10-11.

26 P. P. Edwards, P. A. Anderson and J. M. Thomas, Dissolved alkali metals in zeolites, Acc. Chem. Res., 1996, 29, 23-29.

27 J. L. Dye, M. J. Wagner, G. Overney, R. H. Huang, T. F. Nagy and D. Tománek, Cavities and channels in electrides, J. Am. Chem. Soc., 1996, 118, 7329-7336.

28 V. I. Srdanov, G. D. Stucky, E. Lippmaa and G. Engelhardt, Evidence for an Antiferromagnetic Transition in a ZeoliteSupported Cubic Lattice of F Centers, Phys. Rev. Lett., 1998, 80, 2449-2452.

29 J. L. Dye, Electrons as anions, Science, 2003, 301, 607-608.

30 S. B. Dawes, D. L. Ward, R. H. Huang and J. L. Dye, First electride crystal structure, J. Am. Chem. Soc., 1986, 108, 3534-3535.

31 F. J. Tehan, B. L. Barnett and J. L. Dye, Alkali anions. Preparation and crystal structure of a compound which contains the cryptated sodium cation and the sodium anion, J. Am. Chem. Soc., 1974, 96, 7203-7208.

32 J. L. Dye, J. M. Ceraso, M. L. Tak, B. L. Barnett and F. J. Tehan, Crystalline salt of the sodium anion (Na-), $J$. Am. Chem. Soc., 1974, 96, 608-609.

33 J. Kim, A. S. Ichimura, R. H. Huang, M. Redko, R. C. Phillips, J. E. Jackson and J. L. Dye, Crystalline Salts of Na- and K(Alkalides) that Are Stable at Room Temperature, J. Am. Chem. Soc., 1999, 121, 10666-10667.

34 M. Y. Redko, R. H. Huang, J. E. Jackson, J. F. Harrison and J. L. Dye, Barium Azacryptand Sodide, the First Alkalide with an Alkaline Earth Cation, Also Contains a Novel Dimer, (Na2)2-, J. Am. Chem. Soc., 2003, 125, 2259-2263.

35 W. M. Sun, D. Wu, Y. Li, J. Y. Liu, H. M. He and Z. R. Li, A theoretical study on novel alkaline earth-based excess electron compounds: unique alkalides with considerable nonlinear optical responses, Phys. Chem. Chem. Phys, 2015, 17, 4524-4532.

36 W. Press, P. Damay, F. Leclercq and P. Chieux, On the structure of solid $\mathrm{Ca}(\mathrm{ND} 3) \mathrm{x}$; with $\mathrm{x} \approx 6$, J. Chem. Phys., 1989, 91, 1167-1172.

37 P. Damay, F. Leclercq and P. Chieux, Geometry of the ND3group in a metallic Ca(ND3)6compound and in solid and liquid deuteroammonia as measured by neutron scattering, Phys. Rev. B: Condens. Matter Mater. Phys., 1990, 41, 9676-9682.

38 J. C. Wasse, C. A. Howard, H. Thompson, N. T. Skipper, R. G. Delaplane and A. Wannberg, The structure of calcium-ammonia solutions by neutron diffraction, $J$. Chem. Phys., 2004, 121, 996.
39 T. R. White, D. A. Gordon, R. F. Marzke, R. B. V. Dreele, J. L. Yarnell, A. L. Bowman and W. S. Glaunsinger, Structures and molecular motions in alkaline earth hexammines, Nature, 1978, 271, 414-417.

40 W. S. Glaunsinger, R. B. Von Dreele, R. F. Marzke, R. C. Hanson, P. Chieux, P. Damay and R. Catterall, Structures and properties of metal-ammonia compounds on the trail of a new ammonia geometry, J. Phys. Chem., 1984, 88, 3860-3877.

41 I. C. Hwang, T. Drews and K. Seppelt, $\mathrm{Mg}(\mathrm{NH} 3) 6 \mathrm{Hg} 22$, a Mercury Intercalation Compound, J. Am. Chem. Soc., 2000, 122, 8486-8489.

42 C. H. Christensen, R. Z. Sørensen, T. Johannessen, U. J. Quaade, K. Honkala, T. D. Elmøe, R. Køhler and J. K. Nørskov, Metal ammine complexes for hydrogen storage, J. Mater. Chem., 2005, 15, 4106.

43 J. S. Hummelshøj, R. Z. Sørensen, M. Y. Kustova, T. Johannessen, J. K. Nørskov and C. H. Christensen, Generation of Nanopores during Desorption of NH3 from Mg(NH3)6Cl2, J. Am. Chem. Soc., 2006, 128, 16-17.

44 C. H. Christensen, T. Johannessen, R. Z. Sørensen and J. K. Nørskov, Towards an ammonia-mediated hydrogen economy?, Catal. Today, 2006, 111, 140-144.

45 Y. Liu, R. Ma, R. Luo, K. Luo, M. Gao and H. Pan, Hydrogen Storage Properties of the $\mathrm{Mg}$ (NH3) 6Cl2-LiH Combined System, Mater. Trans., 2011, 52, 627-634.

46 M. H. Sørby, O. M. Løvvik, M. Tsubota, T. Ichikawa, Y. Kojima and B. C. Hauback, Crystal structure and dynamics of $\mathrm{Mg}(\mathrm{ND} 3) 6 \mathrm{Cl} 2$, Phys. Chem. Chem. Phys., 2011, 13, 7644 .

47 F. Castet, V. Rodriguez, J. L. Pozzo, L. Ducasse, A. Plaquet and B. Champagne, Design and characterization of molecular nonlinear optical switches, Acc. Chem. Res., 2013, 46, 2656-2665.

48 N. N. Ma, S. J. Li, L. K. Yan, Y. Q. Qiu and Z. M. Su, Switchable NLO response induced by rotation of metallacarboranes [NiIII/IV(C2B9H11)2]-/0 and C-, B-functionalized derivatives, Dalton Trans., 2014, 43, 5069-5075.

49 A. Plaquet, B. Champagne, J. Kulhanek, F. Bures, E. Bogdan, F. Castet, L. Ducasse and V. Rodriguez, Effects of the Nature and Length of the $\pi$-Conjugated Bridge on the Second-Order Nonlinear Optical Responses of Push-Pull Molecules Including 4,5-Dicyanoimidazole and Their Protonated Forms, ChemPhysChem, 2011, 12, 3245-3252.

50 J. H. Hou, Y. J. Liu, X. Zhang, Q. Duan, D. Y. Jiang, J. M. Qin and R. Q. Zhao, Electric-field-induced nonlinear optical switches of all-metal spherical aromatic molecules with infrared transparency: a theoretical study, New J. Chem., 2018, 42, 1031-1036.

51 M. Nakano, T. Minami, K. Yoneda, S. Muhammad, R. Kishi, Y. Shigeta, T. Kubo, L. Rougier, B. Champagne, K. Kamada and K. Ohta, Giant Enhancement of the Second Hyperpolarizabilities of Open-Shell Singlet Polyaromatic Diphenalenyl Diradicaloids by an External Electric Field and Donor-Acceptor Substitution, J. Phys. Chem. Lett., 2011, 2, 1094-1098. 
52 M. Nakano, B. Champagne, E. Botek, K. Ohta, K. Kamada and T. Kubo, Giant electric field effect on the second hyperpolarizability of symmetric singlet diradical molecules, J. Chem. Phys., 2010, 133, 154302.

53 Y. Bai, Z. J. Zhou, J. J. Wang, Y. Li, D. Wu, W. Chen, Z. R. Li and C. C. Sun, The effects of external electric field: creating non-zero first hyperpolarizability for centrosymmetric benzene and strongly enhancing first hyperpolarizability for non-centrosymmetric edge-modified graphene ribbon H2N-(3,3)ZGNR-NO2, J. Mol. Model., 2013, 19, 3983-3991.

54 W. M. Sun, C. Y. Li, J. Kang, D. Wu, Y. Li, B. L. Ni, X. H. Li and Z. R. Li, Superatom Compounds under Oriented External Electric Fields: Simultaneously Enhanced Bond Energies and Nonlinear Optical Responses, J. Phys. Chem. C, 2018, 122, 7867-7876.

55 A. K. Jissy and A. Datta, Effect of External Electric Field on $\mathrm{H}$-Bonding and $\pi$-Stacking Interactions in Guanine Aggregates, ChemPhysChem, 2012, 13, 4163-4172.

56 A. Susarrey-Arce, R. M. Tiggelaar, M. Morassutto, J. Geerlings, R. G. P. Sanders, B. Geerdink, S. Schlautmann, L. Lefferts, A. vanHouselt and J. G. E. Gardeniers, A new ATR-IR microreactor to study electric field-driven processes, Sens. Actuators, B, 2015, 220, 13-21.

57 P. M. De Biase, D. A. Paggi, F. Doctorovich, P. Hildebrandt, D. A. Estrin, D. H. Murgida and M. A. Marti, Molecular Basis for the Electric Field Modulation of Cytochrome c Structure and Function, J. Am. Chem. Soc., 2009, 131, 16248-16256.

58 M. J. Frisch, G. W. Trucks, H. B. Schlegel, G. E. Scuseria, M. A. Robb, J. R. Cheeseman, G. Scalmani, V. Barone, G. A. Petersson, H. Nakatsuji, X. Li, M. Caricato, A. V. Marenich, J. Bloino, B. G. Janesko, R. Gomperts, B. Mennucci, H. P. Hratchian, J. V. Ortiz, A. F. Izmaylov, J. L. Sonnenberg, D. Williams-Young, F. Ding, F. Lipparini, F. Egidi, J. Goings, B. Peng, A. Petrone, T. Henderson, D. Ranasinghe, V. G. Zakrzewski, J. Gao, N. Rega, G. Zheng, W. Liang, M. Hada, M. Ehara, K. Toyota, R. Fukuda, J. Hasegawa, M. Ishida, T. Nakajima, Y. Honda, O. Kitao, H. Nakai, T. Vreven, K. Throssell, J. A. Montgomery Jr, J. E. Peralta, F. Ogliaro, M. J. Bearpark, J. J. Heyd, E. N. Brothers, K. N. Kudin, V. N. Staroverov, T. A. Keith, R. Kobayashi, J. Normand, K. Raghavachari, A. P. Rendell, J. C. Burant, S. S. Iyengar, J. Tomasi, M. Cossi, J. M. Millam, M. Klene, C. Adamo, R. Cammi, J. W. Ochterski, R. L. Martin, K. Morokuma, O. Farkas, J. B. Foresman and D. J. Fox, Gaussian16, version B.01, Gaussian Inc., Wallingford CT, 2016.

59 T. Yanai, D. P. Tew and N. C. Handy, A new hybrid exchangecorrelation functional using the Coulomb-attenuating method (CAM-B3LYP), Chem. Phys. Lett., 2004, 393, 51-57.

60 Y. Tawada, T. Tsuneda, S. Yanagisawa, T. Yanai and K. Hirao, A long-range-corrected time-dependent density functional theory, J. Chem. Phys., 2004, 120, 8425-8433.

61 W. M. Sun, D. Wu, Y. Li and Z. R. Li, Substituent Effects on the Structural Features and Nonlinear Optical Properties of the Organic Alkalide $\mathrm{Li}+($ calix[4]pyrrole $) \mathrm{Li}-$, ChemPhysChem, 2013, 14, 408-416.

62 M. Niu, G. T. Yu, G. H. Yang, W. Chen, X. G. Zhao and X. R. Huang, Doping the Alkali Atom: An Effective Strategy to Improve the Electronic and Nonlinear Optical Properties of the Inorganic Al12N12 Nanocage, Inorg. Chem., 2014, 53, 349-358.

63 W. M. Sun, D. Wu, Y. Li and Z. R. Li, Theoretical study on superalkali (Li3) in ammonia: Novel alkalides with considerably large first hyperpolarizabilities, Dalton Trans., 2014, 43, 486-494.

64 S. J. Wang, Y. Li, Y. F. Wang, D. Wu and Z. R. Li, Structures and nonlinear optical properties of the endohedral metallofullerene-superhalogen compounds Li@ C 60-BX 4 (X= F, Cl, Br), Phys. Chem. Chem. Phys., 2013, 15, 1290312910.

65 W. M. Sun, X. H. Li, J. Wu, J. M. Lan, C. Y. Li, D. Wu, Y. Li and Z. R. Li, Can Coinage Metal Atoms Be Capable of Serving as an Excess Electron Source of Alkalides with Considerable Nonlinear Optical Responses?, Inorg. Chem., 2017, 56, 4594-4600.

66 P. A. Limacher, K. V. Mikkelsen and H. P. Lüthi, On the accurate calculation of polarizabilities and second hyperpolarizabilities of polyacetylene oligomer chains using the CAM-B3LYP density functional, J. Chem. Phys., 2009, 130, 194114.

67 A. D. McLean and G. S. Chandler, Contracted Gaussian basis sets for molecular calculations. I. Second row atoms, $\mathrm{Z}=11-$ 18, J. Chem. Phys., 1980, 72, 5639-5648.

68 E. Gross, J. Dobson and M. Petersilka, Density Functional Theory of Time-Dependent Phenomena, in Density Functional Theory II, Springer, 1996, pp. 81-172.

69 T. Lu and F. W. Chen, Multiwfn: a multifunctional wavefunction analyzer, J. Comput. Chem., 2012, 33, 580-592.

70 K. Sasagane, F. Aiga and R. Itoh, Higher-order response theory based on the quasienergy derivatives: The derivation of the frequency-dependent polarizabilities and hyperpolarizabilities, J. Chem. Phys., 1993, 99, 3738-3778.

71 S. Yamada, M. Nakano, I. Shigemoto and K. Yamaguchi, Static second hyperpolarizabilities $\gamma$ of nitroxide radical and formaldehyde: evaluation of spatial contributions to $\gamma$ by a hyperpolarizability density analysis, Chem. Phys. Lett., 1996, 254, 158-164.

72 H. Y. Wu, A. Chaudhari and S. Lee, Theoretical studies on nonlinear optical properties of formaldehyde oligomers by ab initio and density functional theory methods, J. Comput. Chem., 2005, 26, 1543-1564.

73 J. Boixel, V. Guerchais, H. L. Bozec, A. Chantzis, D. Jacquemin, A. Colombo, C. Dragonetti, D. Marinottoe and D. Robertode, Sequential double second-order nonlinear optical switch by an acido-triggered photochromic cyclometallated platinum(II) complex, Chem. Commun., 2015, 51, 7805-7808.

74 G. Q. Mei, H. Y. Zhang and W. Q. Liao, A symmetry breaking phase transition-triggered high-temperature solid-state quadratic nonlinear optical switch coupled with 
a switchable dielectric constant in an organic-inorganic hybrid compound, Chem. Commun., 2016, 52, 11135-11138.

75 M. Torrent-Sucarrat, J. M. Anglada and J. M. Luis, Evaluation of the nonlinear optical properties for annulenes with Huckel and Mobius topologies, J. Chem. Theory Comput., 2011, 7, 3935-3943.

76 M. Garcia-Borràs, M. Solà, J. M. Luis and B. Kirtman, Electronic and vibrational nonlinear optical properties of five representative electrides, J. Chem. Theory Comput., 2012, 8, 2688-2697.

77 J. M. Luis, J. Martí, M. Duran, J. L. Andrés and B. Kirtman, Nuclear relaxation contribution to static and dynamic (infinite frequency approximation) nonlinear optical properties by means of electrical property expansions: Application to $\mathrm{HF}, \mathrm{CH} 4, \mathrm{CF} 4$, and SF6, J. Chem. Phys., 1998, 108, 4123-4130.

78 J. M. Luis, M. Duran, B. Champagne and B. Kirtman, Determination of vibrational polarizabilities and hyperpolarizabilities using field-induced coordinates, $J$. Chem. Phys., 2000, 113, 5203-5213.

79 J. M. Luis, M. Duran, B. Champagne and B. Kirtman, Calculation of static zero-point vibrational averaging corrections and other vibrational curvature contributions to polarizabilities and hyperpolarizabilities using field-induced coordinates, Int. J. Quantum Chem., 2000, 80, 471-479. 